\title{
Perancangan Data Warehouse pada Laporan PDPT di Kopertis Wilayah V
}

\author{
Designing Data Warehouse at PDPT Report in Kopertis Wilayah V \\ Sukarsono Windu Kumoro*1, Abidarin Rosidi ${ }^{2}$, Armadyah Amborowati ${ }^{3}$ \\ 1,2,3 Magister Teknik Informatika STMIK AMIKOM Yogyakarta \\ E-mail: *1﹎.windu_k@yahoo.com, ${ }^{2}$ abi@amikom.ac.id, ${ }^{3}$ armadyah.a@amikom.ac.id
}

\begin{abstract}
Abstrak
Evaluasi terhadap Program Studi pada Perguruan Tinggi Swasta (PTS) yang memperoleh Ijin Penyelenggaraan dari Dirjen Dikti dibutuhkan oleh Koordinator Kopertis Wilayah V. Laporan PDPT telah terkumpul sejak tahun akademik 2002 semester ganjil (2002-1) sampai dengan tahun akademik 2013 semester genap (2013-2) yang terdiri dari data transaksi yang terkait dengan proses belajar mengajar di PTS. Laporan PDPT dari PTS dikerjakan atas dasar "Culture Trust". Untuk mengatasi permasalahan tersebut dibangun sebuah data warehouse di Kopertis Wilayah V DIY. Data warehouse ini dikembangkan dengan menggunakan Foxpro dan Clipper dikarenakan data yang dilaporkan menggunakan file berekstendi DBF. Foxpro dan Clipper adalah sebuah paket basisdata dan dapat didistribusikan.Dalam pengerjaan pembangunan data warehouse ini akan melalui proses ETL dan pembuatan Star Schema (Skema Bintang) berupa dimensi-dimensi yang terhubung dengan tabel fakta berupa tabel aktifitas perkuliahan mahasiswa, evaluasi program studi dan aktifitas dosen mengajar di seluruh program studi pada PTS yang menjadi binaan Kopertis Wilayah V. Kemudian hasil data warehouse akan dianalisa melalui proses OLAP (On-line Analytical Processing).
\end{abstract}

Kata Kunci - PDPT, DataWarehouse, ETL, OLAP, Star Schema, DBF.

\begin{abstract}
The evaluation of the Program on Private Higher Education (PTS) which derive from the Operating Licence required by the Coordinator General of Higher Education Kopertis Region V. PDPT reports have been collected since 2002 semester of the academic year (2002-1) until the second semester of academic year 2013 (2013-2), which consists of transaction data associated with the teaching and learning process in the PTS. PDPT reports of PTS is done on the basis of "Culture Trust". To overcome these problems built a data warehouse in Kopertis Region V DIY. The data warehouse was developed using FoxPro and Clipper because the data reported using a DBF file extension. FoxPro and Clipper is a package database and can be distributed. In the executionof data warehouse development is going through the ETL process and the making of Star Schema (Star Schema) in the form of dimensions that are connected with the fact table in the form of table activity lecturing students, evaluation of courses and activities throughout the faculty teaching courses at private universities being built Kopertis region $V$. Then the results will be analyzed data warehouse through a process of OLAP (On-line Analytical Processing).
\end{abstract}

Keywords - PDPT, Data Warehousing, ETL, OLAP, Star Schema, DBF. 


\section{PENDAHULUAN}

Evaluasi program studi merupakan tahapan kegiatan yang sangat penting dan harus dilaksanakan oleh setiap program studi maupun badan penyelenggara perguruan tinggi. Dalam program pendataan dan evaluasi ini, setiap program studi yang mendapatkan ijin penyelenggaraan dari Dirjen Dikti Kemdikbud diwajibkan menyerahkan laporan penyelenggaraan program studinya yang disebut laporan Evaluasi Program Studi Berbasis Evaluasi Diri (EPSBED) mulai tahun akademik 2002/2003 pada semester ganjil. Pada tahun 2009 pihak Direktorat Jenderal Pendidikan Tinggi Kementerian Pendidikan Nasional mengganti nama EPSBED tersebut menjadi Pangkalan Data Pendidikan Tinggi yang lazim disebut sebagai laporan PDPT.

Perangkat lunak yang dikembangkan oleh Direktorat Jenderal Pendidikan Tinggi fungsinya baru sebatas mengkoleksi data, sehingga fasilitas yang ada pada perangkat lunak tersebut belum dapat memenuhi kebutuhan Kopertis Wilayah V.Data yang sudah terkumpul dan ukurannya yang sangat besar tersebut belum dapat mendukung pengambilan keputusan yang harus dilakukan oleh pihak Kopertis Wilayah V secara keseluruhan. Selain itu, belum dapat diketahui bagaimana PTS tersebut melakukan proses belajar mengajar di kampusnya, apakah PTS tersebut taat azas atau melakukan pelanggaran. Kekurangan lain, belum dapat diketahui perkembangannya apakah PTS layak untuk direkomendasikan perpanjangan ijin operasionalnya ataukah direkomendasikan untuk ditutup dikaitkan dengan pemenuhan standar minimal yang ditentukan dari pemerintah.

Rumusan masalah penelitian ini adalah bagaimana merancang sebuah data warehouse terhadap laporan PDPT yang telah diserahkan kepada Dirjen Dikti melalui Kopertis Wilayah V agar dapat dilakukan evaluasi dengan lebih mudah. Perancangan data warehouse pada laporan PDPT bertujuan untuk memberikan kemudahan kepada Kopertis Wilayah V untuk melihat dan mengelola data yang sangat besar dari seluruh PTS di Daerah Istimewa Yogyakarta, sehingga dalam menentukan langkah pengawasan, pengendalian, pembinaan, tidak salah arah serta untuk mendukung kebijakan bagi pimpinan Kopertis Wilayah V.

\section{METODE PENELITIAN}

Penelitian ini dilakukan dengan langkah-langkah seperti berikut:

1. Pengumpulan seluruh data laporan semester dari PTS yang berada di lingkungan Kopertis Wilayah V yang berupa keping CD (CompactDisk).

2. Melakukan penyalinan data dari CD ke Harddisk.

3. Setelah isi semua CD disalin ke Harddisk maka untuk selanjutnya dilakukan kompilasi data data laporan tersebut ke dalam folder masing masing PTS. Pada kegiatan ini peneliti melibatkan seluruh operator PDPT pada masing masing PTS agar kompilasi dapat berjalan efektif dan efisien. Dalam hal ini ada keuntungan yang dapat diambil yaitu pihak Kopertis memiliki kumpulan data transaksional mulai dari semester 2002-1 sampai dengan 2013-2 dan pihak PTS dapat menyalin atau mendapatkan duplikat dari seluruh laporan yang pernah diserahkan ke Kopertis Wilayah V.

4. Setelah diperoleh softcopy data transaksional, maka dilakukan proses ETL.

5. Setelah proses ETL selesai dilanjutkan dengan penulisan program aplikasi dengan bahasa Foxpro. Bahasa ini dipilih dikarenakan data yang telah terkumpul formatnya adalah DBF. Analisa yang dipakai pada penelitian ini adalah Reporting.

6. Tahap selanjutnya adalah tahap pengetesan program aplikasi. Pada Tahap ini peneliti membagikan program aplikasi kepada masing masing PTS di DIY untuk dilakukan pengetesan terhadap data yang dimiliki masing-masing PTS.

7. Hasil yang didapat diserahkan kepada pihak Kopertis Wilayah V untuk dilakukan pembinaan terhadap program studi yang melanggar ataupun melakukan proses belajar mengajar yang tidak taat azas. 


\subsection{Metode Pengumpulan Data}

Pengumpulan data dilakukan dengan cara melakukan kompilasi seluruh data laporan PDPT yang telah diserahkan oleh seluruh PTS di DIY ke Dirjen Dikti Kemdikbud melalui Kopertis Wilayah V DIY dalam bentuk CD (CompactDisk) dengan mengundang seluruh operator PDPT seluruh PTS untuk melakukan kompilasi data secara bersama-sama dalam 3 (tiga) tahap pertemuan.

\subsection{Metode Analisis Data}

Data yang dikumpulkan adalah seluruh data laporan proses belajar mengajar pada seluruh program studi pada PTS di lingkungan Kopertis Wilayah V. Data yang telah terkumpul dianalisa menggunakan Reporting. Reporting digunakan untuk menjawab pertanyaan penelitian dan permintaan pengguna. Informasi yang dihasilkan dari reporting berupa daftar yang ditampilkan pada layar komputer sehingga pengambil keputusan dapat mengetahui pelanggaran yang dilakukan oleh pengelola program studi [1].

\section{HASIL DAN PEMBAHASAN}

Analisis sistem yang akan dibangun pada penelitian ini terdiri dari proses pengumpulan data sampai dengan membangun CUBE. Termasuk di dalamnya terdapat proses Extract, Transform and Loading (ETL). ETL merupakan proses pencarian data, integrasi dan entri data ke dalam data warehouse [2]. Agar penelitian ini dapat berjalan sesuai dengan rencana, maka perlu dibuat alur penelitian. Alur penelitian ini mulai dari penentuan subyek DataWarehouse sampai dengan bagaimana cara menganalisis DataWarehouse menggunakan Reporting[3].

Pada tahap awal akan ditentukan apa yang menjadi subyek Data Warehouse yang akan dibuat. Subyek Data Warehouse pada penelitian ini adalah Laporan Pangkalan Data Pendidikan Tinggi (PDPT) pada PTS di lingkungan Kopertis Wilayah V.Langkah selanjutnya adalah mendefinisikan sumber data yang akan dipakai sebagai data sumber. Pada penelitian ini yang akan dipakai sebagai sumber data adalah data laporan PDPT dari seluruh PTS yang ada di Kopertis Wilayah V DIY sejak semester 2002-1 sampai dengan 2013-2. Data data dimaksud terdiri dari seluruh data transaksi akademik mahasiswa, kurikulum dan transaksi akademik dosen/ tenaga pengajar.

Setelah sumber data ditentukan, selanjutnya merancang skema bintang dan mendesain ETL Pada penelitian ini akan dirancang skema bintang dengan banyak tabel fakta dikarenakan banyaknya reporting yang akan ditampilkan. Adapun pada proses ETL akan dilakukan proses mapping, proses cleaning dan pada tahap akhir akan dilakukan proses loading[4]. Sejak proses awal sampai dengan loading, peneliti akan melakukan penulisan script sendiri dikarenakan perangkat lunak yang digunakan adalah perangkat lunak Foxpro dan Clipper.

Setelah merancang skema bintang dan merancang ETL dilakukan, proses selanjutnya adalah melakukan proses ETL itu sendiri yaitu merekam data data yang ada di file sumber sampai terekam pada tabel dimensi dan tabel fakta. Yang pada akhirnya secara logika membentuk cube. Proses terakhir adalah melakukan analisis dengan menggunakan reporting.

Perancangan Skema Bintang terhadap data Laporan Pangkalan Data Pendidikan Tinggi (PDPT) dengan tabel transaksional sebagai berikut:
1. MSPTI : Master Perguruan Tinggi.
2. MSPST : Master Program Studi.
3. MSMHS : Master Mahasiswa.
4. TBDOS : Tabel Master Dosen (NIDN).
5. TBKMK : Tabel Kurikulum/Matakuliah.
6. TRAKM : Transaksi Aktivitas Kuliah Mahasiswa.
7. TRNLM : Transaksi Nilai Semester Mahasiswa.
8. TRLSM : Transaksi Mahasiswa Lulus/Cuti/Keluar/D.O/Non-aktif. 
9. TRAKD : Transaksi Mengajar Dosen.

10. TRKAP : Transaksi Kapasitas Mahasiswa Baru.

11. TBPTI : Tabel Perguruan Tinggi untuk referensi.

12. TBPST : Tabel Program Studi untuk Referensi.

13. TBPRO : Tabel Propinsi dan Kabupaten untuk referensi.

14. TBKOD : Tabel Kode Aplikasi untuk referensi

Seperti yang ditunjukkan pada Gambar 1, skema yang dihasilkan adalah skema bintang dengan banyak tabel fakta dan tabel dimensi, yaitu:

1. Tabel Fakta Aktifitas Mahasiswa.

2. Tabel Fakta Aktifitas Dosen.

3. Tabel Fakta Evaluasi Program Studi

Sedangkan untuk tabel dimensi adalah:

1. Tabel Dimensi Semester.

2. Tabel Dimensi Perguruan Tinggi.

3. Tabel Dimensi Program Studi.

4. Tabel Dimensi Mahasiswa.

5. Tabel Dimensi Dosen (NIDN).

6. Tabel Dimensi Kurikulum.

7. Tabel Dimensi Aktifitas Kuliah Mahasiswa.

8. Tabel Dimensi Nilai Semester Mahasiswa.

9. Tabel Dimensi Aktifitas Dosen Mengajar.

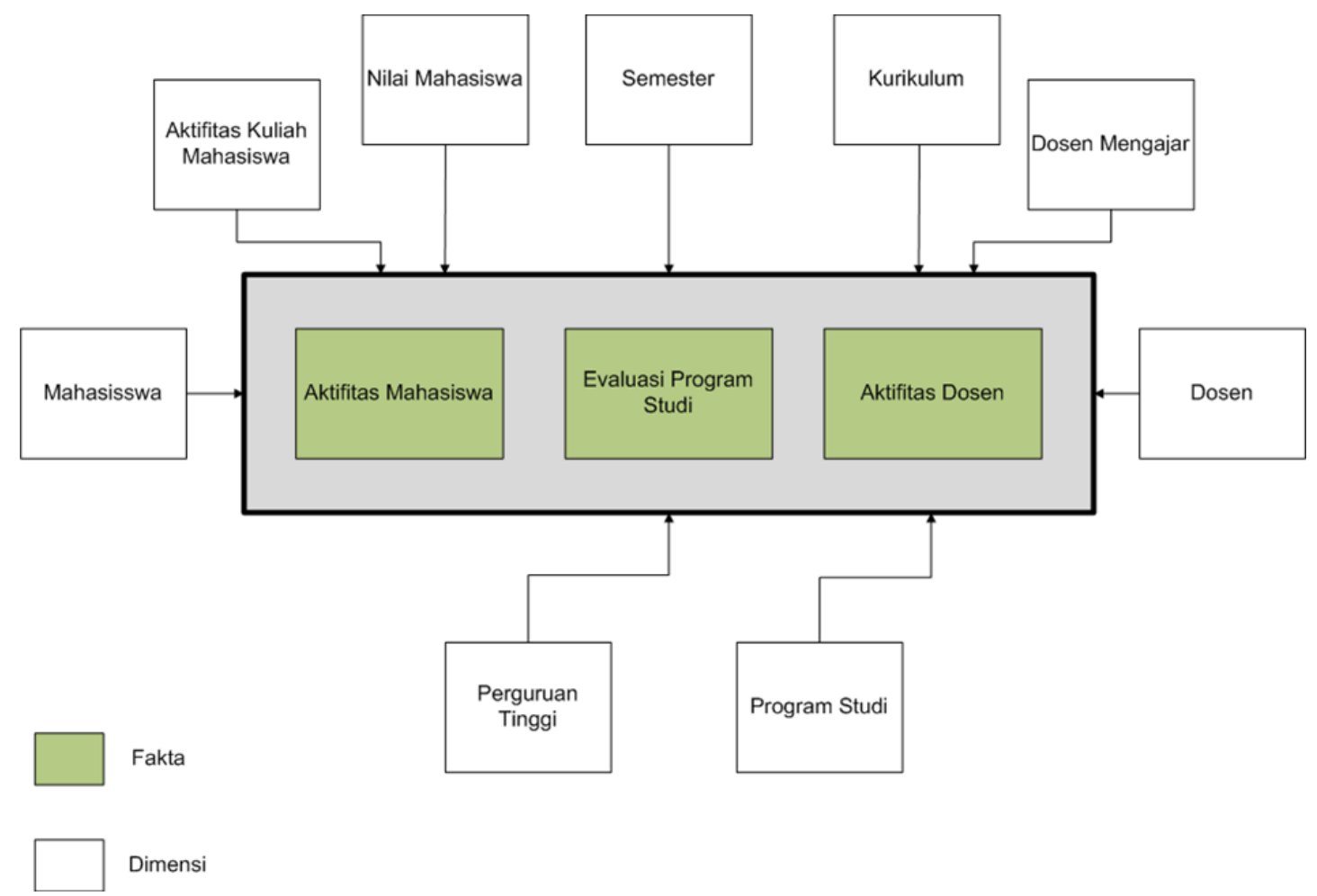

\section{Gambar1. Skema Data Warehouse}

Data tersebut dilakukan proses gabung data agar pada setiap semester dikompilasi menjadi data seluruh semester. Data yang sama dijadikan satu sehingga tidak ada duplikasi data pada setiap tabel. Untuk penggabungan data ini dilakukan penulisan script sendiri dengan menggunakan perangkat lunak Foxpro. 
Citec Journal, Vol. 3, No. 3, Mei 2016 - Juli 2016

ISSN: 2354-5771

Setelah dijalankan, maka akan terbentuk kumpulan tabel transaksi yang merupakan gabungan dari seluruh tabel transaksi dari PTS dan seluruh semester mulai sejak semester 20021 sampai dengan 2013-2. Kumpulan tabel transaksi ini yang nantinya akan dilakukan proses Extract, Transfer, Loading (ETL) sehingga data-data tersebut akan mengisi tabel Fakta dan tabel Dimensi.Setelah terbentuk kumpulan tabel transaksi dari masing masing PTS, nantinya tabel tabel ini akan digunakan sebagai sumber data untuk pembuatan Data Warehouse.

Untuk mewujudkan tampilan berupa reporting terhadap data data yang diolah, tampilan yang terkait dengan penyajian data warehouse yang dikemas dalam menu menu. Pada saat program aplikasi dijalankan, secara otomatis data yang dipilih hanya terkait dengan data PTS terpilih, seperti tampak pada Gambar 2. Setelah halaman utama ditampilkan, pengguna diminta untuk memilih salah satu program studi untuk dianalisis, ditunjukkan pada Gambar 3. Setelah salah satu program studi dipilih, akan ditampilkan sub menu pilihan analisis terhadap program studi dimaksud. Sebagai contoh apabila yang dipilih adalah analisis nomor 2 yakni pilihan terhadap analisis mahasiswa dan transaksi akademiknya, hasilnya akan ditampilkan sub menu, seperti ditunjukkan pada Gambar 4. Adapun Gambar 5 merupakan contoh apabila pengguna memilih nomor pilihan 3 yaitu Daftar mahasiswa yang diurutkan berdasar pada nama mahasiswa.

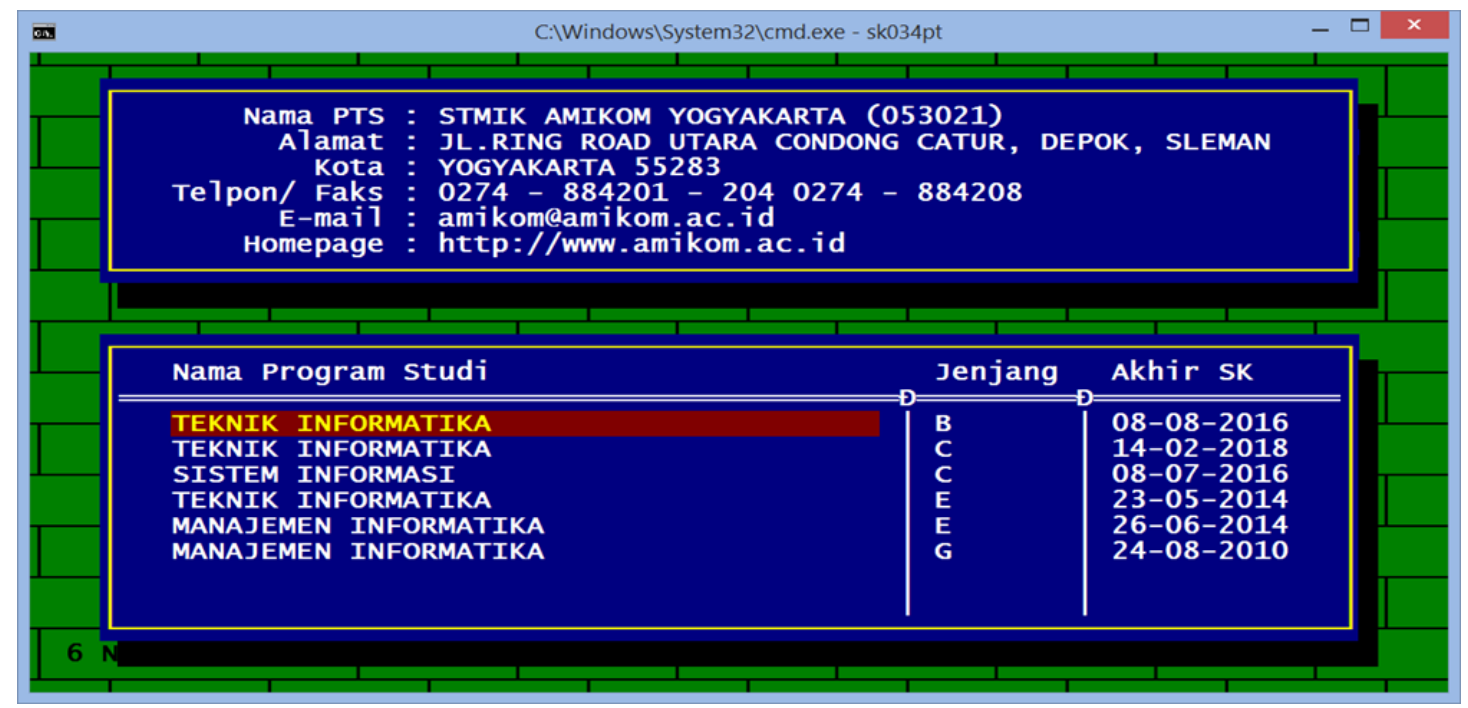

Gambar 2. Menu Utama pada Program Aplikasi

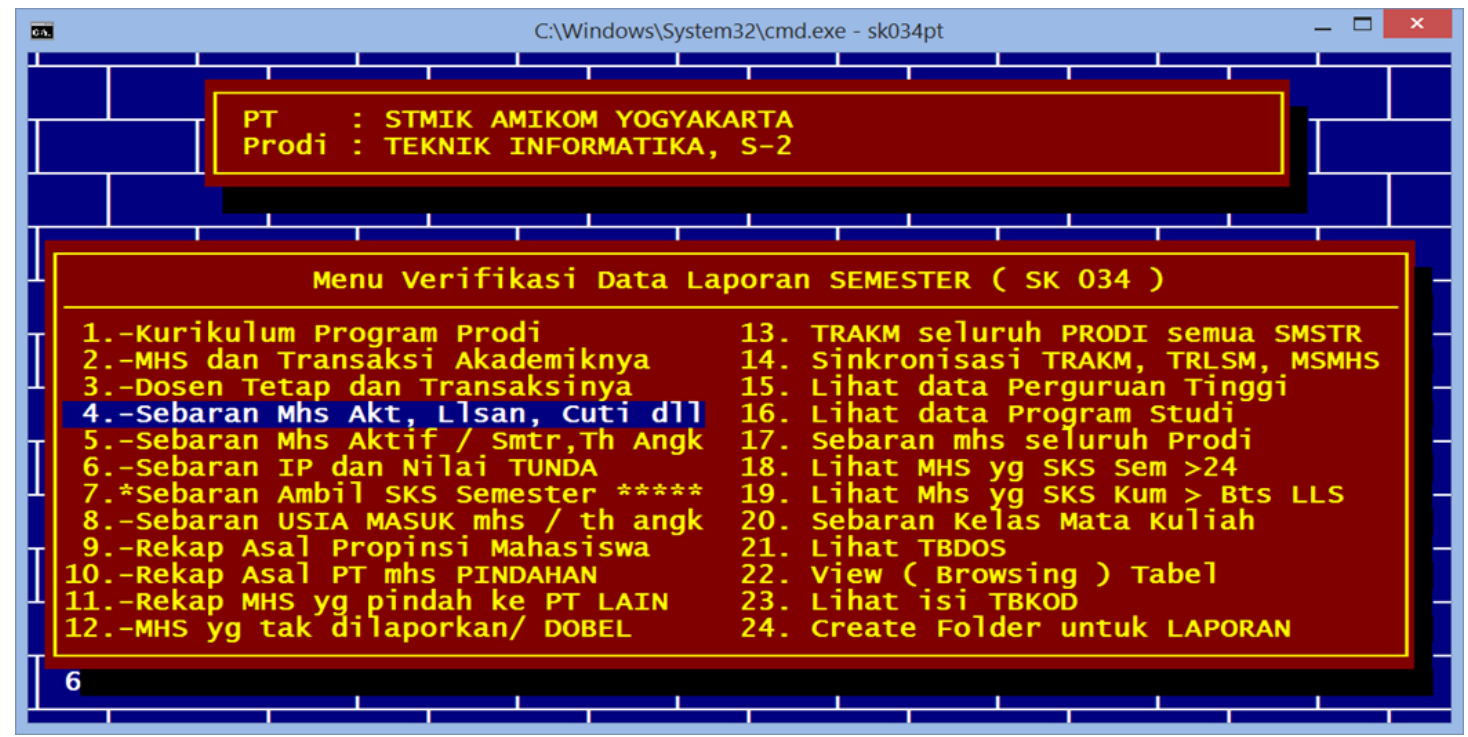

Gambar 3. Sub Menu pada Program Aplikasi Data Warehouse 


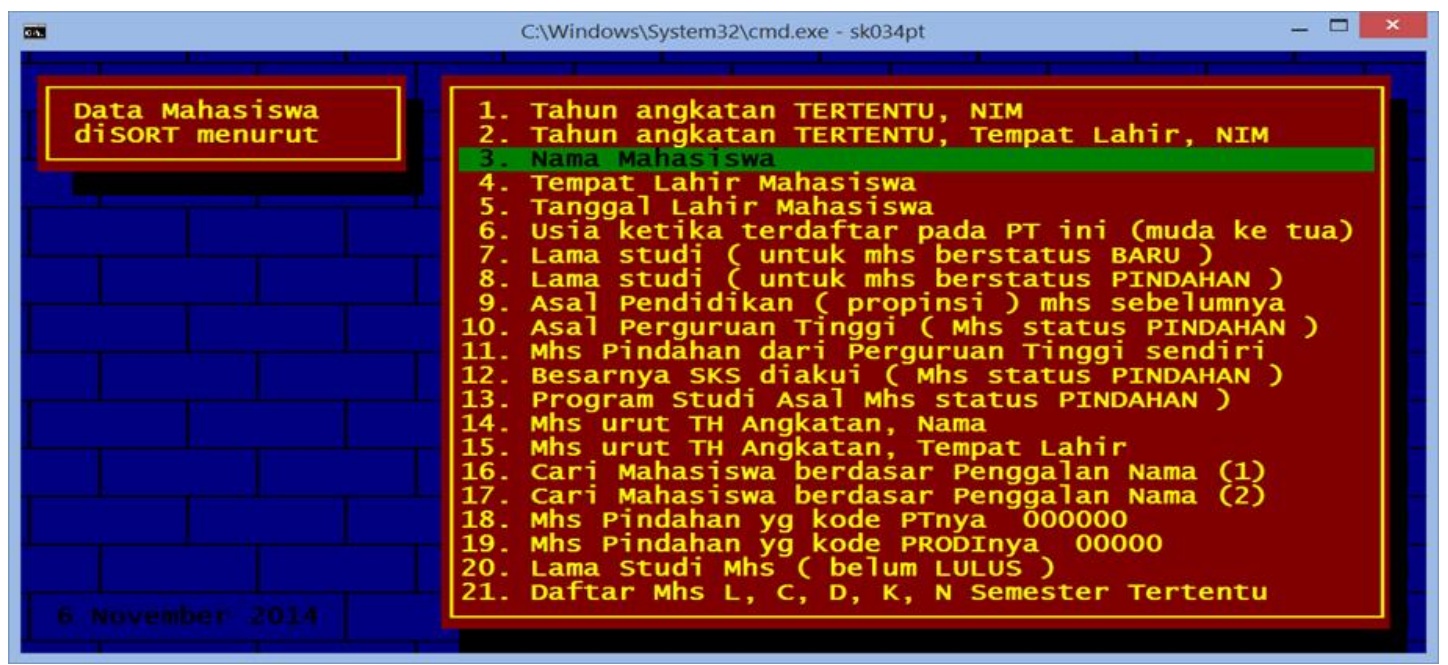

Gambar 4. Menu Pilihan Evaluasi Transaksi Mahasiswa

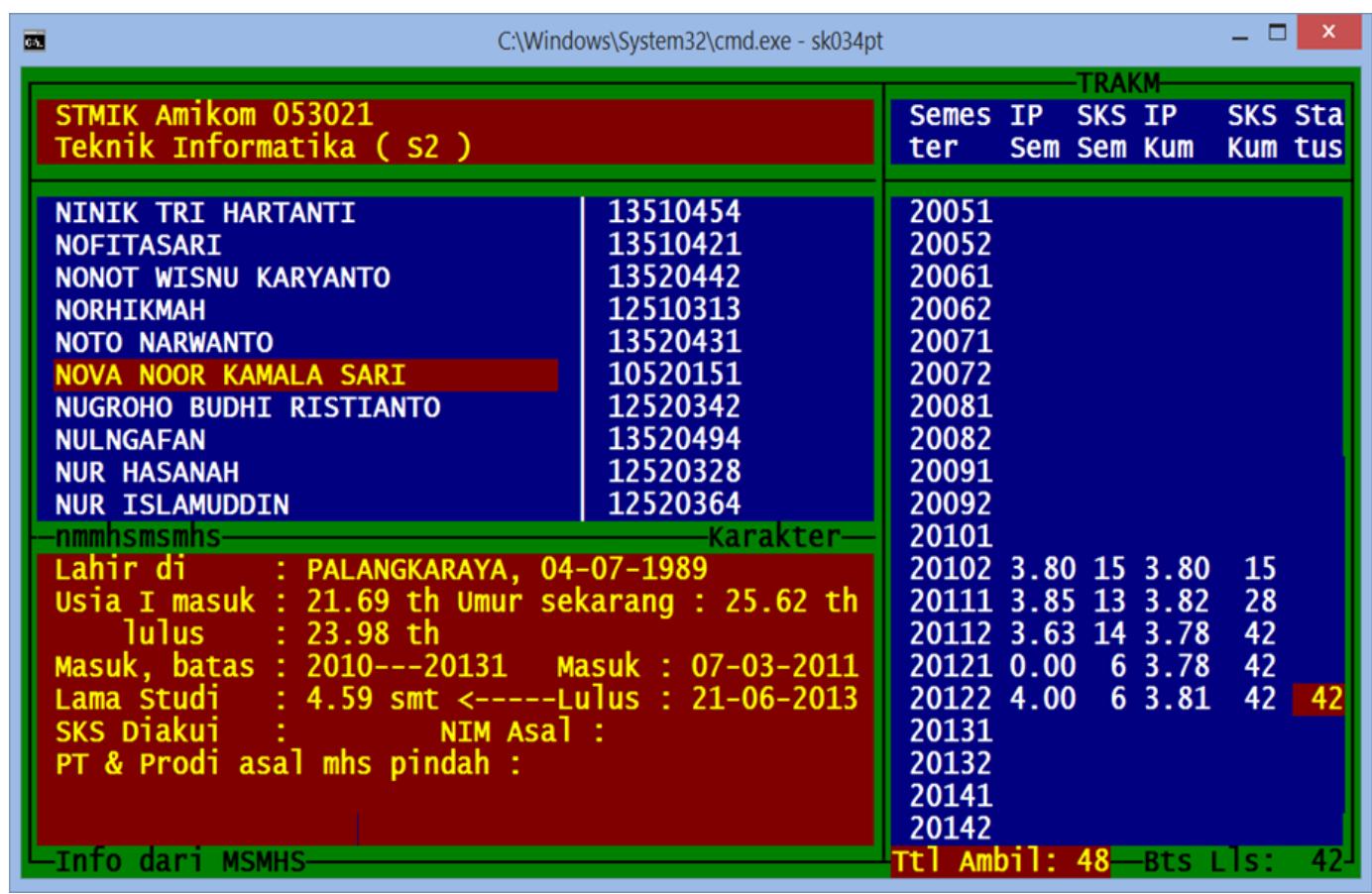

Gambar 5. Contoh tampilan sebaran perolehan SKS dan IP

Tabel hasil penggabungan yang akan dilakukan ekstrak terdiri dari record yang sangat banyak sehingga ukuran tabelnya juga sangat besar. Sebelum record yang ada pada master data, tabel dimensi dan tabel fakta harus dikosongkan terlebih dahulu. Adapun perintah dalam Foxpro adalah dengan menuliskan script

use xxxx.dbf

zap

use

Apabila script tersebut dijalankan maka tabel yang sedang dibuka akan dihapus seluruh record yang ada atau dengan kata lain tabel tersebut dikosongkan dan hanya terdiri dari struktur tabel saja. Tabel dimensi yang sudah dikosongkan recordnya dapat dilihat pada Gambar 6 . 
Citec Journal, Vol. 3, No. 3, Mei 2016 - Juli 2016

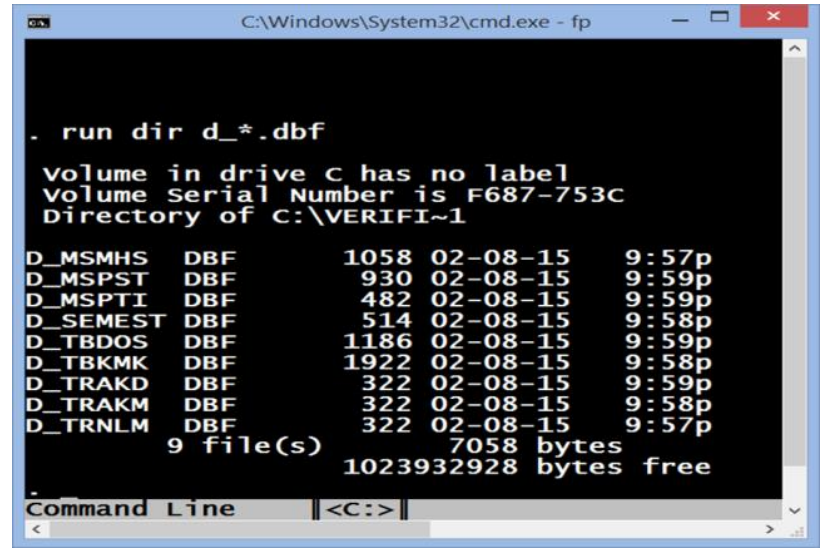

Gambar 6. Tabel Dimensi setelah dikosongkan

Setelah tabel dimensi dikosongkan, tabel fakta juga dikosongkan dengan cara seperti melakukan pengosongan record pada tabel dimensi yang ditunjukkan pada Gambar 7, untuk selanjutnya dilakukan penarikan data dari basis data pada data warehouse.

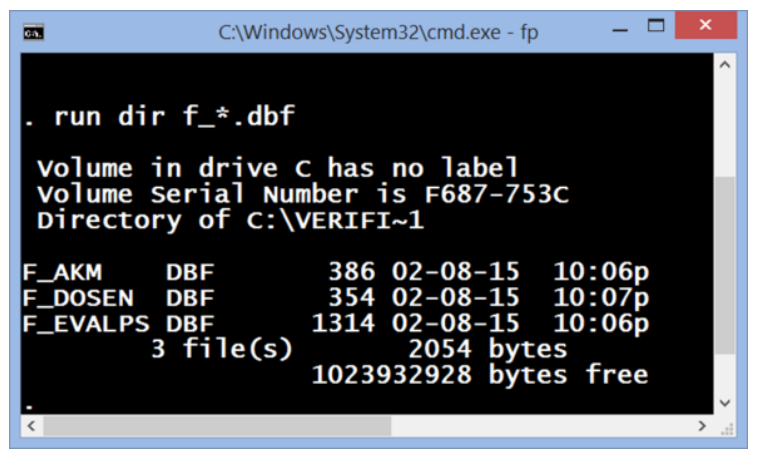

Gambar 7. Tabel Fakta setelah dikosongkan

Pada proses transformnoise pada data warehouse tidak diperbolehkan karena akan mengakibatkan kesalahan pada hasil pengolahan analisis, sehingga informasi yang didapat akan menjadi tidak benar. Contoh noise pada data adalah adanya nilai null pada sebuah field, adanya ketidakonsistenan pada isi field, contohnya seperti penulisan isi field NIM yang seharusnya '09.52.0170' ternyata pada data sumber, tercatat ' 9.52 .0170 ' atau contoh lainnya adalah penulisan jenis kelamin yang seharusnya ' $\mathrm{P}$ ' menyatakan 'perempuan', akan tetapi pada data sumber ' $\mathrm{P}$ ' menyatakan 'pria', dan beberapa contoh lainnya mengenai ketidak-konsistenan data. Seluruh isi field dari data sumber tidak ada yang berisi 'null' dan tidak terdapat data yang tidak konsisten seperti yang telah dijabarkan sebelumnya. Hal tersebut dikarenakan pada PDPT yang telah dilaporkan ternyata data sudah melalui proses validasi.

Pada proses loading, proses penarikan data dari data hasil proses ekstraksi yang sudah bersih dari noise. Setelah proses penarikan data dilakukan maka akan dapat diketahui bahwa data yang berada pada tabel dimensi dan tabel fakta sangat jauh berbeda dari sisi ukuran/besarnya data. Semula data transaksi yang ada besarnya sekitar 199 GB, sedangkan setelah dilakukan loading yang diletakkan pada tabel dimensi dan tabel fakta menjadi hanya sebesar 1.78 GB saja yang berarti $0.894 \%$ seperti terlihat pada Gambar 8 . 


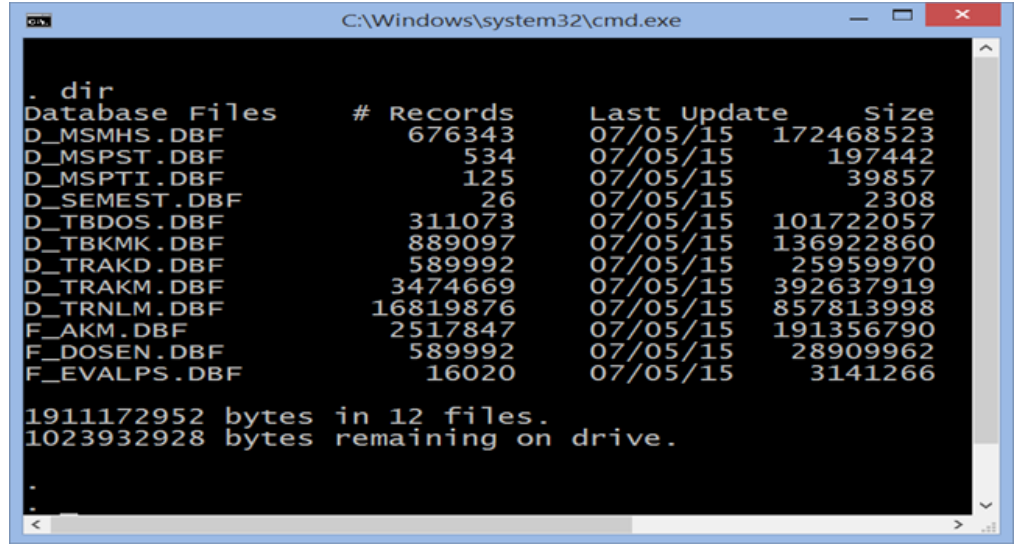

Gambar 8. Kondisi Tabel Fakta dan Tabel Dimensi setelah Loading

Analisis hasil dilakukan menggunakan reporting terhadap data data yang ada pada tabel dimensi dan tabel fakta. Reporting yang dihasilkan merupakan rangkuman hasil wawancara kebutuhan informasi dengan pihak manajemen Kopertis Wilayah V terhadap laporan yang telah diserahkan.

1. Sebaran Asal Propinsi Mahasiswa

Data mahasiswa yang dilaporkan terdiri dari data diri, transaksi akademik dan data nilai pindahan/transfer. Pada data diri mahasiswa terdapat beberapa item data yang salah satunya adalah asal propinsi mahasiswa. Setelah proses ETL dapat diketahui bahwa pada setiap Program Studi di PTS mahasiswanya berasal dari propinsi mana saja di lingkungan negara Indonesia. Pada Gambar 9 dapat dilihat bahwa ternyata mahasiswa yang berasal dari propinsi DIY terbanyak pada tahun 2013. Sedangkan mahasiswa yang berasal dari propinsi selain DIY pada tahun 2013 dan 2014 tidak ada yang mendaftar.

Analisis hasil dilakukan menggunakan reporting terhadap data data yang ada pada tabel dimensi dan tabel fakta. Reporting yang dihasilkan merupakan rangkuman hasil wawancara kebutuhan informasi dengan pihak manajemen Kopertis Wilayah V terhadap laporan yang telah diserahkan.

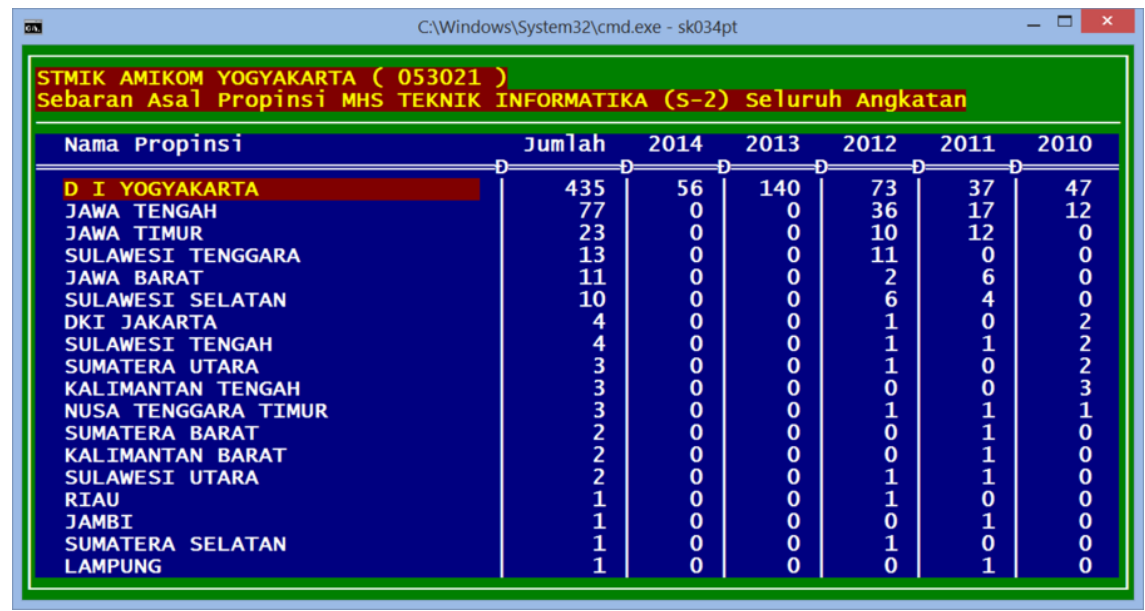

Gambar 9. Sebaran asal Propinsi mahasiswa

2. Sebaran Tujuan PT Pindahan

Pada saat mencari asal mahasiswa pindahan, maka sumber data yang ditelusuri adalah laporan dari PTS yang dipilih. Dalam hal ini dapat dijelaskan bahwa apabila akan dicari mahasiswa yang pindah dari perguruan tinggi lain ke STMIK AMIKOM, maka data yang ditelusuri adalah laporan yang dibuat oleh STMIK AMIKOM seperti terlihat pada Gambar 10. 
Citec Journal, Vol. 3, No. 3, Mei 2016 - Juli 2016

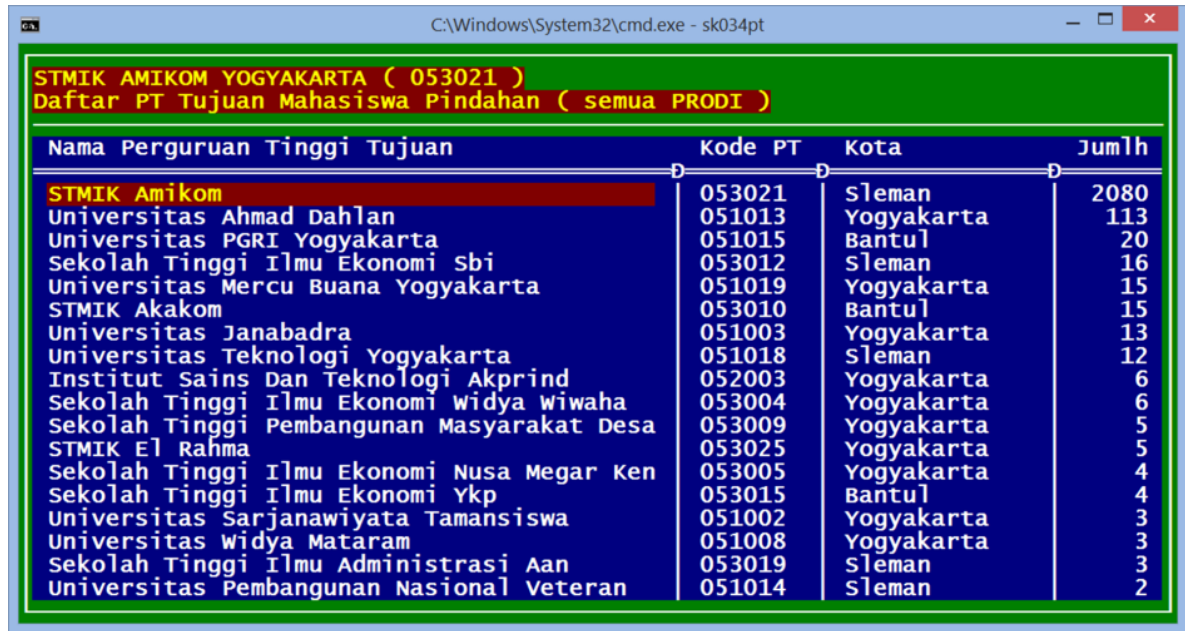

Gambar 10. Contoh PT tujuan mahasiswa pindahan

3. Sebaran Asal Perguruan Tinggi Mahasiswa Pindahan

Mahasiswa yang pindah dari kampus ke kampus lain bisa saja pindah dikarenakan keluar dari kampus asal atau yang bersangkutan alih jalur. Misalkan dari Jenjang D3 ke jenjang S1. Sedangkan mahasiswa yang pindah dari dalam kampus sendiri bisa saja melanjutkan studi ke jenjang yang lebih tinggi atau sudah pernah keluar dari kampus kemudian masuk lagi dengan nomor induk mahasiswa yang baru. Data sebaran asal perguruan tinggi mahasiswa pindahan dapat dilihat pada Gambar 11.

\begin{tabular}{|c|c|c|c|}
\hline \multicolumn{3}{|c|}{ C:IWindows $\backslash$ System $321 \mathrm{cmd}$.exe - sk034pt } & $-\square x$ \\
\hline \multicolumn{4}{|c|}{$\begin{array}{l}\text { STMIK AMIKOM YOGYAKARTA ( } 053021 \text { ) } \\
\text { Daftar PT Asal Mahasiswa Pindahan ( semua PRODI ) }\end{array}$} \\
\hline Asal Perguruan Tinggi & Kode PT & Kota & Jum7h \\
\hline $\begin{array}{l}\text { STMIK Amikom } \\
\text { Universitas Sebelas Maret } \\
\text { Universitas Gadjah Mada } \\
\text { Universitas Negeri Semarang } \\
\text { AMIK Cipta Darma } \\
\text { Politeknik Negeri Banjarmasin } \\
\text { Institut Teknologi Telkom } \\
\text { Politeknik Telkom } \\
\text { Universitas Sains Dan Teknologi Jayapura } \\
\text { Politeknik Negeri Pontianak } \\
\text { Politeknik Pos Indonesia } \\
\text { Universitas Diponegoro } \\
\text { Institut Pertanian Bogor } \\
\text { Politeknik Negeri Semarang } \\
\text { Politeknik Elektronik Negeri Surabaya } \\
\text { Universitas Muhammadiyah Metro } \\
\text { AMIK AKMI } \\
\text { Universitas Ahmad Dahlan }\end{array}$ & $\begin{array}{l}053021 \\
001027 \\
001001 \\
001041 \\
064049 \\
005015 \\
042008 \\
045035 \\
121008 \\
005011 \\
045009 \\
001008 \\
002003 \\
005005 \\
005018 \\
021004 \\
024063 \\
051013\end{array}$ & $\begin{array}{l}\text { Sleman } \\
\text { Surakarta } \\
\text { Yogyakarta } \\
\text { Semarang } \\
\text { Surakarta } \\
\text { Banjarmasin } \\
\text { Bandung } \\
\text { Bandung } \\
\text { Jayapura } \\
\text { Pont ianak } \\
\text { Bandung } \\
\text { Semarang } \\
\text { Bogor } \\
\text { Semarang } \\
\text { Surabaya } \\
\text { Metro } \\
\text { Baturaja } \\
\text { Yogyakarta }\end{array}$ & $\begin{array}{r}2160 \\
27 \\
22 \\
13 \\
6 \\
3 \\
3 \\
3 \\
3 \\
2 \\
2 \\
1 \\
1 \\
1 \\
1 \\
1 \\
1 \\
1\end{array}$ \\
\hline
\end{tabular}

Gambar 11. Daftar PT asal mahasiswa Pindahan

4. Sebaran Status Mahasiswa pada Program Studi

Apabila pada semester berjalan seorang mahasiswa statusnya Keluar, Lulus atau DO maka pada semester berikutnya tentunya tidak boleh ada statusnya lagi. Bila pada semester berjalan seorang mahasiswa berstatus Aktif, Cuti atau Non Aktif maka pada semester berikutnya mahasiswa tersebut harus ada statusnya. Kemungkinan status mahasiswa tersebut pada semester berikutnya bisa saja Aktif, Lulus, Cuti, Non Aktif atau DO. Apabila seorang mahasiswa pada semester berjalan distatuskan Lulus, maka sudah pasti mahasiswa tersebut harus distatuskan Aktif juga dan yang bersangkutan harus mengambil Mata Kuliah. Untuk mengetahui apakah Program 
Studi sudah menyerahkan seluruh transaksi aktifitas mahasiswanya atau belum, dalam program dibuat dua rumus yaitu rumus Posisi Awal dan Posisi Akhir seperti berikut.

Awal $=($ Aktif + Cuti+Non Aktif + Keluar+DO $)$-Baru

Akhir $=($ Aktif + Cuti+Non Aktif-Lulus $)$

Implementasi dari kedua rumus tersebut adalah dengan cara membandingkan antara posisi Awal semester sekarang dikurangi Akhir posisi semester lalu. Hasilnya tidak boleh $>0$ atau $<0$. Apabila selisihnya $<>0$, maka berarti pengelola program studi belum melaporkan seluruh transaksi aktifitas mahasiswa yang ada pada program studinya. Pada gambar 12 dapat diketahui bahwa pada kolom SELISIH masih terdapat angka bukan 0 (nol), yang berarti pengelola program studi belum melaporkan seluruh status aktifitas mahasiswanya.

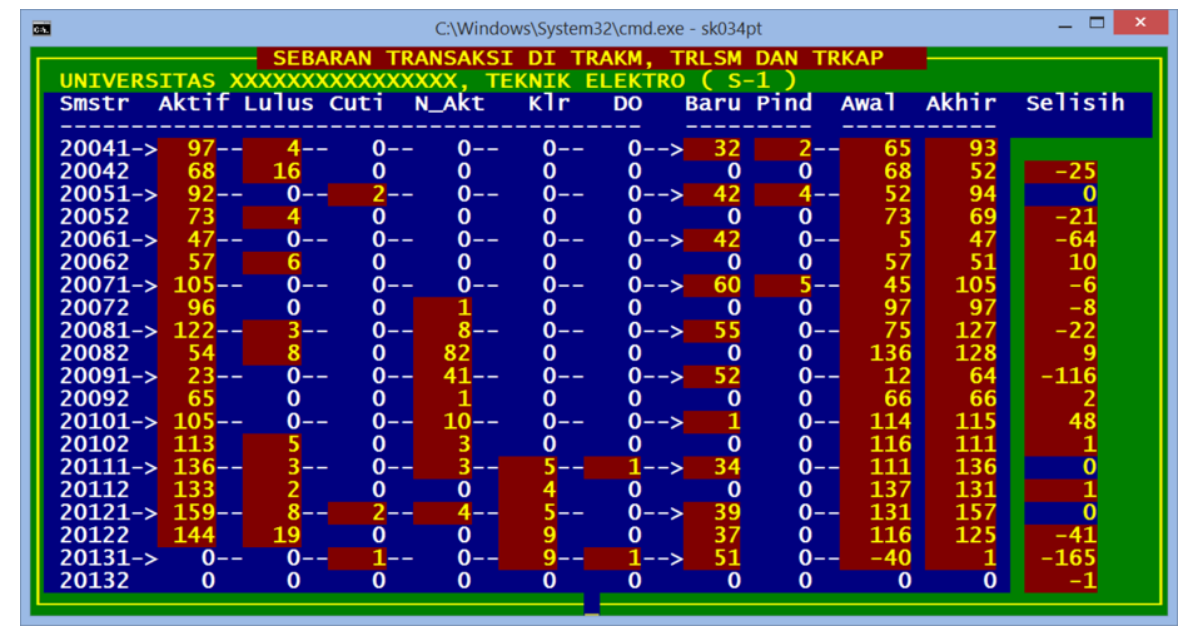

Gambar 12. Sebaran Transaksi Akademik Mahasiswa yang belum benar

5. Sebaran Penawaran Mata Kuliah

Pada analisis reporting ini dapat diketahui apakah PTS dalam melaporkan kurikulum terjadi penulisan mata kuliah yang sama beberapa kali dan apakah mata kuliah tersebut pelaksanaannya sudah sesuai dengan rencana alokasi semesternya. Pada Gambar 13 dapat dilihat contoh pelaksanaan kurikulum pada Akademi Kebidanan Yogyakarta Program Studi Kebidanan Jenjang D3. Pada laporan semester 2013-1 dapat diketahui bahwa mata kuliah yang ditawarkan pada semester 1 telah diambil oleh mahasiswa dengan jumlah peserta 256 (dua ratus lima puluh enam) mahasiswa. Jadi dapat diketahui bahwa mata kuliah yang ditawarkan pada semester ganjil juga diambil oleh mahasiswa yang saat itu sedang bearada pada semester ganjil.

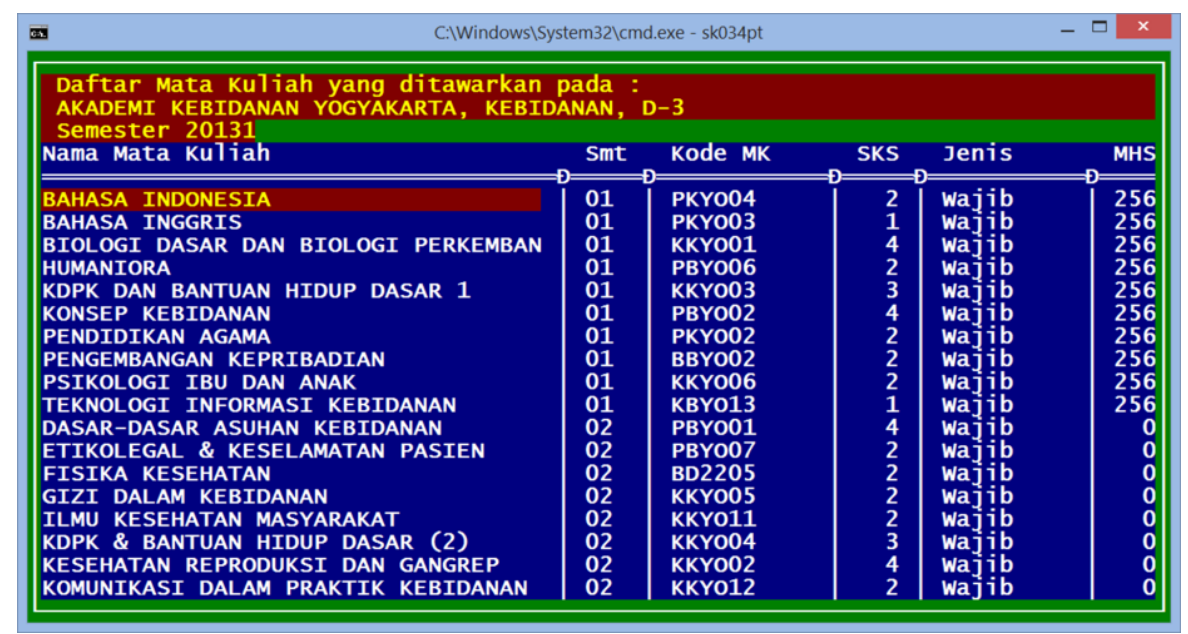

Gambar 13 Daftar Mata Kuliah yang ditawarkan pada semester tertentu 
6. Sebaran Aktifitas Perkuliahan Mahasiswa

Setiap mahasiswa pada PTS terdaftar pada salah satu program studi jenjang tertentu. Misalkan saja mahasiswa A terdaftar pada PTS B program studi Teknik Informatika Jenjang S1. Mahasiswa A tersebut mulai kuliah pada semester 2010-1. Sejak mahasiswa A tersebut terdaftar aktif sebagai mahasiswa di PTS B Program Studi Teknik Informatika Jenjang S1 tersebut, kemungkinan yang terjadi pada semester berikutnya bisa saja mahasiswa A tersebut statusnya Aktif, Cuti, Non Aktif, Keluar atau Drop Out (DO).Apabila pada semester berjalan seorang mahasiswa statusnya Keluar, Lulus atau DO maka pada semester berikutnya tentunya tidak boleh ada statusnya lagi. Bila pada semester berjalan seorang mahasiswa berstatus Aktif, Cuti atau Non Aktif maka pada semester berikutnya mahasiswa tersebut harus ada statusnya. Kemungkinan status mahasiswa tersebut pada semester berikutnya bisa saja Aktif, Lulus, Cuti, Non Aktif atau DO. Apabila seorang mahasiswa pada semester berjalan distatuskan Lulus, maka sudah pasti mahasiswa tersebut harus distatuskan Aktif juga dan yang bersangkutan harus mengambil Mata Kuliah. Apabila seorang mahasiswa didatakan pindahan, maka darimana asal Perguruan Tinggi dan besarnya sks bawaan juga harus didatakan dengan benar.

\section{Sebaran Perolehan IP Semester dan Nilai Tunda}

Yang dimaksud dengan nilai tunda adalah nilai pada mata kuliah yang telah diambil oleh mahasiswa, tetapi sampai batas waktu semester berakhir nilai tersebut belum diberikan oleh dosen yang menguji mata kuliah tersebut. Memang tidak semua nilai tuda harus diberikan. Sebagai contoh apabila seorang mahasiswa mengambil mata kuliah Skripsi atau Tesis dan ketika semester berakhir mahasiswa belum menyelesaikan, maka nilai mata kuliah tersebut harus diberi nilai Tunda (T) Namun jumlah nilai tunda mata kuliah Skripsi atau Tesis tergantung pada Jenjang Program Studinya. Untuk Skripsi jumlah nilai tundanya paling banyak sekitar 25\% dari jumlah mahasiswa yang aktif. Sedangkan untuk jenjang S2 jumlah nilai tunda untuk mata kuliah Tesis biasanya tidak lebih dari $25 \%$ dari jumlah mahasiswa yang aktif pada semester itu. Apabila ada nilai tunda selain mata kuliah yang disebutkan di atas maka seharusnya pihak pengelola program studi menagih kepada dosen pengujinya untuk segera memberikan nilai akhir. Pada kolom Nilai Kosong dimaksudkan ada berapa satuan mata kuliah orang yang tidak ada isi nilainya. Pada Pelaporan PDPT tidak diperkenankan laporan perolehan nilai dengan hasil nilai kosong (tidak ada isinya). Nilai E tidak sama dengan nilai kosong dikarenakan nilai kosong tidak terdapat pada referensi tabel bobot nilai. Sebaran perolehan IP semester dan nilai tunda dapat dilihat pada Gambar 14.

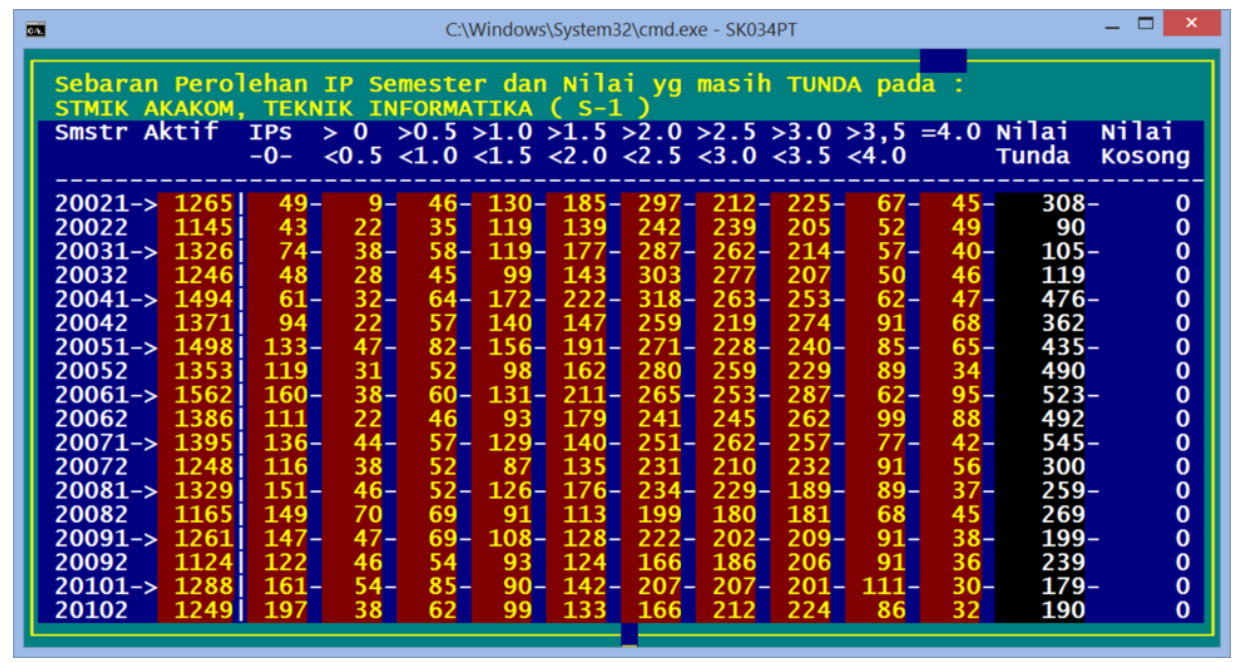

Gambar 14. Sebaran perolehan IP Semester dan Nilai yang masih Tunda 
8. Sebaran Aktifitas Dosen Mengajar

Pada Gambar 15 diketahui bahwa ada dosen yang pada semester 2010-2 melaksanakan tugas mengajar pada program studi Kebidanan jenjang D3 sebanyak 49 (empat puluh sembilan) kelas. Hal ini tentunya menarik perhatian dikarenakan kewajaran seorang dosen melaksanakan tugas mengajar adalah 12 (dua belas) sks per minggu.Setelah dicermati lebih lanjut dapat diketahui bahwa dosen tersebut dalam melaksanakan tugasnya ternyata pada kelas yang jumlah pertemuannya relatif sedikit.Pada kelas reguler dengan kurikulum reguler biasanya jumlah pertemuan dalam satu semester berkisar antara 15 sampai dengan 16 pertemuan.

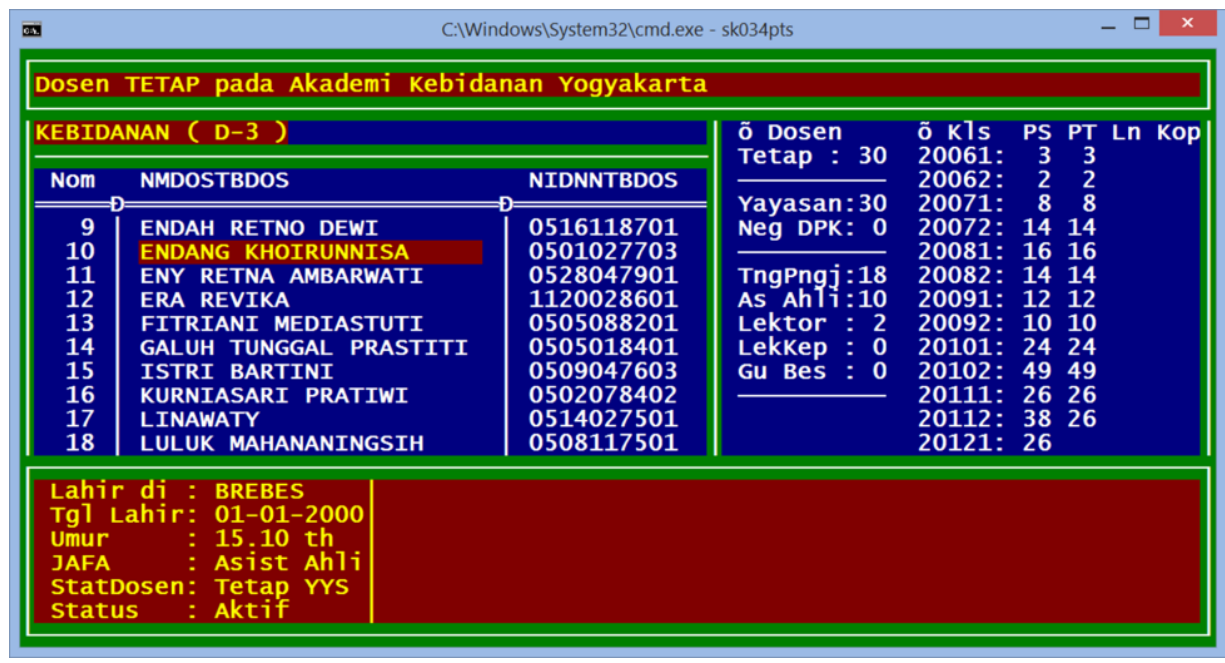

Gambar 15. Sebaran Transaksi Mengajar Dosen

\section{KESIMPULAN}

Berdasarkan hasil penelitian yang telah dilakukan, dapat disimpulkan sebagai berikut:

1. Perancangan data warehouse dan aplikasi berbasis desktop menggunakan bahasa pemrogaman Foxpro dan Clipper dengan menggunakan OLAP di dalamnya telah dapat dibangun.

2. Tampilan antar muka yang sederhana dan fasilitas untuk dapat langsung melihat hasil rekapitulasi data yang dibutuhkan, telah memberikan solusi alternatif kemudahan.

3. Setelah dilakukan penelitian ternyata masih terdapat pelanggaran atau perilaku tidak taat azas dari pengelola program studi.

4. Program studi masih belum melaporkan seluruh transaksi akademik mahasiswanya.

5. Perguruan tinggi masih belum cermat dalam menerima mahasiswa pindahan dengan terbukti adanya pemalsuan transkrip akademik.

\section{SARAN} adalah:

Adapun saran yang bisa diberikan untuk pengembangan lebih lanjut dari sistem ini

1. Perluasan lingkup data yang diolah tidak hanya sebatas perolehan SKS, Indeks Prestasi Semester, maupun Indeks Prestasi Kumulatif serta transaksi dosen mengajar saja.

2. Pemilihan tabel dimensi dan tabel fakta yang lebih banyak sehingga data yang dapat dianalisa dan digali menjadi lebih banyak lagi sehingga informasi yang didapat menjadi lebih banyak.

3. Menerapkan query yang lebih baik untuk ETL dan menambah fasilitas untuk melakukan ETL secara otomatis pada aplikasi. 
Citec Journal, Vol. 3, No. 3, Mei 2016 - Juli 2016

\section{DAFTAR PUSTAKA}

[1] Turban, E., 2005, Sistem Pendukung Keputusandan Sistem Cerdas edisi 7 jilid 1, Penerbit Andi, Yogyakarta.

[2] Gustiawan, I., 2006, Data Warehouse, http://myhut.org/public/datawarehouse.doc, diakses tanggal 16 September 2014.

[3] Amborowati, A., 2008, Perancangan dan Pembuatan Data Warehouse pada Perpustakaan STMIK AMIKOM Yogyakarta, Tesis, Program Studi Magister Teknologi Informasi Jurusan Teknik Elektro, Universitas Gadjah Mada, Yogyakarta.

[4] Connoly, T. C., 1999, Database Systems: A Practical Approach to Design, Implementation, and Managemen England, Addison-Wesley, Boston. 